\title{
On the Cultivation of Design Ability in Environmental Design Education
}

\author{
Zhao Yin \\ Xi’an Siyuan Univeisity, Shaanxi, China, 710038
}

Keywords: ethnic cultural design; personnel training model; colleges and universities; reform

\begin{abstract}
This paper explores the reform and innovation methods of college environmental design talents training model based on the concept of ethnic cultural design. In the national culture design teaching idea research, with national characteristics content mining, teaching method exploration, project guidance, teaching content service, and undergraduate and master training system convergence, curriculum evaluation mechanism is designed to improve the specific methods of teaching reform in depth to help achieve environmental design personnel training services in colleges and universities, and jointly promote the environmental design professional discipline development teaching reform goals.
\end{abstract}

\section{Introduction}

By investigating the needs of local environmental design front-line workers, design companies need technical personnel who truly have practical design capabilities. Practical design capabilities include basic design capabilities and distinctive design capabilities that meet Party A's special needs.

\section{Problems in Current Environmental Design Talents Training Model}

At present, some graduates of environmental design majored in colleges and universities can only complete the basic environmental design, and cannot complete the design of characteristic programs. This leads to the design of supporting staff only after they enter the work unit, and cannot become independent designers. This highlights the existing deficiencies and deficiencies in the environmental design professional teaching and personnel training system. The reasons for this result are as follows. 1. Environmental design talent cultivation Professional characteristics do not highlight the university in environmental design teaching highlights the basis of artistic theory and basic ideas inspired, lack of awareness of national culture design[1]. The current training program for environmental design professionals has the problem of emphasizing the cultivation of basic design skills and ignoring the ability of national characteristics. Since environmental design is an applied and comprehensive discipline, personnel training needs to be based on market demand. The training of environmental design talents in colleges and universities needs to be tailored to local specific needs and cultivate talents with national characteristics and design capabilities. 2. The environmental design teaching model is similar. At present, some colleges and universities have similar environmental professional curriculum structure and lack their own professional characteristics. Environmental design major is an artistic, engineering and multidisciplinary discipline. This requires educators to break the inherent art education methods in teaching content and methods. The environmental design disciplines need to combine the professional characteristics and the students' quality to make innovations in the talent cultivation model. On the basis of completing the basic design ability training, targeted teaching modules for ethnic cultures and regional cultures were introduced. In the environmental design teaching, the design basis was integrated into the national culture, the teaching features of the environmental design were highlighted, and the identical teaching model was broken. 3. The lack of connection between environmental design and national culture design the lack of connection between environmental design majors and other disciplines makes it difficult to stimulate design creativity that integrates students and ethnic cultures. Environmental design is a complex specialty involving architecture, 
planning, landscape space, and interior space design. However, the existing curriculum system lacks infiltration with ethnic cultures. Students master isolated, one-sided, fragmented knowledge, and no outstanding ones[2]. The theme of design incorporates this knowledge. The students' professional knowledge did not form a distinctive system. 4. The content of the environmental design teaching is out of touch with the needs of local talents. The previous teaching model of the environmental design profession was relatively rigid, and the teaching content was out of touch with the requirements of local practical design projects, making it a weak link in college education. If we only adjust the local teaching model and plan, and we don't start from the reform of the specific teaching content, it will be difficult for the environmental design talents to meet the needs of talents in the environmental design market in Guangxi.Environmental design model quality decline curve as shown below.

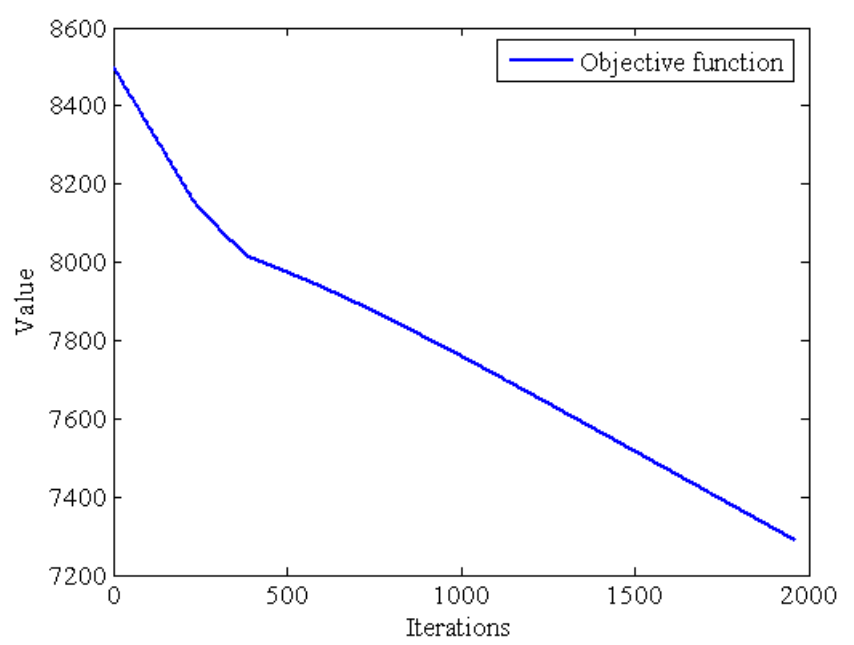

Fig.1 Environmental design model quality decline curve

\section{Reform Method of Environmental Design Talents Training Mode in Colleges and Universities under the Concept of Ethnic Culture Design}

In order to meet the needs of local environmental design talents, colleges and universities in environmental design professional education need to actively explore the characteristics of ethnic culture design under the concept of environmental design talent training model, and then effectively guarantee the quality of teaching. The reform of the talent training model for environmental design professionals can be carried out through research on the teaching concepts of ethnic culture design, content mining of ethnic characteristics, exploration of teaching methods, project guidance, local and undergraduate and master training systems for teaching content, and conversion of curriculum evaluation subjects. 1. Integrate national culture and regional design concepts in environmental design teaching Integrate national cultural design teaching concepts into environmental design teaching concepts, guide teachers and students to broaden their perspectives, view environmental design majors from a higher design level, and break from the concept In the past, the classroom focused only on the drawbacks of the basic design ability of the environmental design professional. Instead, it fully introduced the national culture into the overall teaching of environmental design[3]. It strived to change from the teaching that emphasized the basic design ability of the classroom in the past to the integration of classroom learning and extracurricular learning. Students in different nationality and regional characteristics of the design project, learn and understand the project cultural background and local employers targeted practical needs, and apply to environmental design teaching. 2. Revise the corresponding characteristic teaching plan in the environment design teaching The environmental design major must adjust and revise the original teaching plan and the teaching plan in order to meet the personnel training demand. In the original teaching curriculum, ethnology, sociology, and other types of teaching courses should be appropriately added. At the same time, integrated professional design content should be added to the traditional environmental design curriculum (for example, adding interior design to the traditional interior decoration of 
traditional houses in Guangxi. The relationship between the relationship, landscape design and characteristics of the city's features, etc., makes the content of environmental design clear and the coverage of teaching content is broader. In the specific design teaching modules, such as garden design, road landscape design, and small space design, the national culture design is the core of the establishment of the teaching system. The teaching content centers on how to integrate the regional and national cultural characteristics with the environmental design. arrangement. The revision of the teaching plan starts from the two aspects of content optimization and structure optimization, allowing students to transform from a single basic talented person to a national culturally engineered talented person. 3. The use of scientific and educational collaborative teaching methods and means, combined with classroom teaching and national cultural design scientific research projects Most university teachers' research projects are related to national cultural studies, and so are horizontal design projects. The teaching of environmental design adopts a synergistic teaching model of science and education, which in itself has the inherent advantages of fitting local cultural features or ethnic characteristics. In teaching, teachers must break through the shackles of teaching methods taught in single classrooms in the past, explore how to use national cultural design research projects as guides, guide students to participate in the specific design of local practical projects, and analyze and explain the national cultural background through specific projects.The following is the formula for the calculation of scientific and educational collaboration services.

$$
Z=\left(\begin{array}{c}
Z_{0} \\
Z_{1} \\
\vdots \\
Z_{m}
\end{array}\right)=\left[\begin{array}{cccc}
Z_{01} & Z_{02} & \cdots & Z_{0 n} \\
Z_{11} & Z_{12} & \cdots & Z_{1 n} \\
\cdots & \cdots & \cdots & \cdots \\
Z_{m 1} & Z_{m 2} & \cdots & Z_{m n}
\end{array}\right],(1 \leq i \leq m, 1 \leq j \leq n)
$$

\section{Significance of Environmental Design Talents Training Mode in Colleges and Universities under the Concept of Ethnic Culture Design}

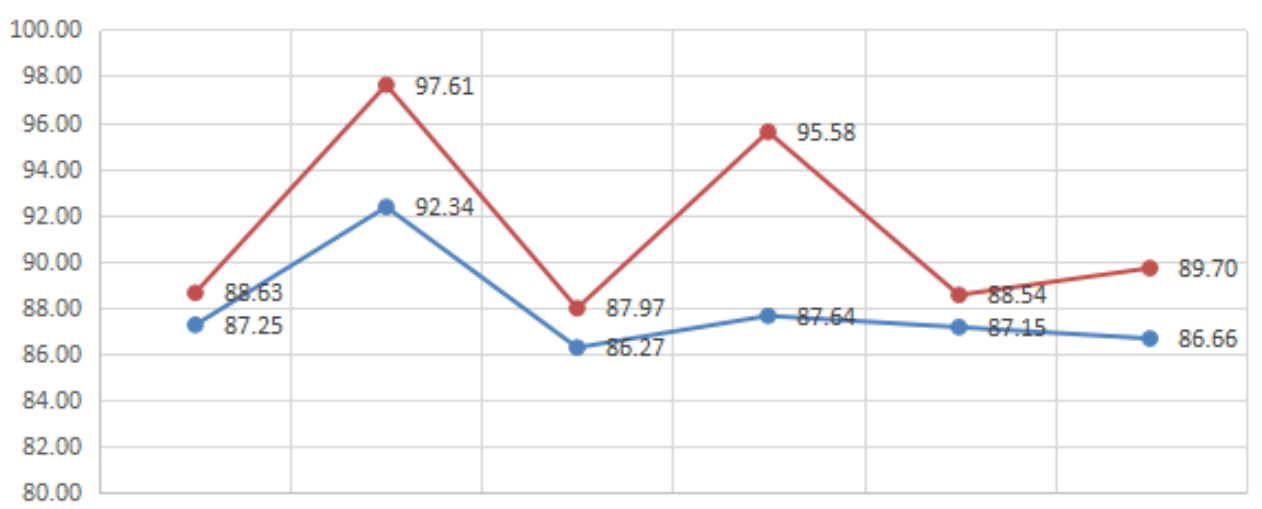

Fig.2 Changes in the scores after the reform of the environmental design model

Based on the concept of ethnic culture design, the reform of environmental design talents training model, its value lies in changing the previous training model of environmental design professionals only pay attention to the training of basic professional design ability, ignoring the national cultural design ability education, lack of personnel characteristics, professional Lack of features and other issues. At the level of personnel training, we fundamentally solve the problem of the disconnect between talent training and the needs of local talent. In the past, environmental design teaching started from the basics of basic design abilities, and there was no design education philosophy of ethnic cultural design. The establishment of a model for the training of talents with ethnic cultural design features will continue to enhance the effectiveness of environmental design professional teaching, highlight the professional characteristics of local colleges and universities, and promote the construction and development of college environmental design majors[4]. Specifically, cultivating characteristic environmental design talents with ethnic cultural design capabilities is conducive to adapting environmental design professionals to the talent needs of local 
local environmental design companies and broadening the employment channels of students. This is of practical significance and is conducive to stimulating students' learning and design. The changes in the scores after the reform of the environmental design model are shown in the following figures. Red is the post-reform and Blue is the pre-reform.

\section{Conclusion}

The training of environmental design professionals needs to start from market demand. In the teaching content, emphasis is placed on the characteristics of the region and the national culture, and the concept of national culture is permeated throughout the education content system. Using the educational innovation theory that integrates the design of national cultures, explore the training model for environmental design professionals in universities, guide the construction of the environmental design professional curriculum system, and continuously enhance the effectiveness of teaching related to environmental design, and finally explore a set of effective national cultural designs. The cultivation model and system of talented environmental design talents have made active reform exploration and practice for the integration of environmental design majors with local construction and the establishment of the professional characteristics of universities.

\section{References}

[1] Meryem Yalçin. "Exploratory” and "Descriptive” Aspects of Environmental Psychology Course within the Interior Design Education [J]. Procedia - Social and Behavioral Sciences, 2015,174.

[2] Banu Garip, Ervin Garip. Addressing Environmental Design in Interior Architecture Education: Reflections on the Interior Design Studio [J]. Procedia - Social and Behavioral Sciences, 2012, 51.

[3] Deniz Deniz. Sustainable Thinking and Environmental Awareness through Design Education [J]. Procedia Environmental Sciences, 2016, 34.

[4] Brian Muller, Travis Flohr. A Geodesign approach to environmental design education: Framing the pedagogy, evaluating the results [J]. Landscape and Urban Planning, 2016,156. 